\title{
Comparison of the effects of salmeterol/fluticasone propionate with fluticasone propionate on airway physiology in adults with mild
} persistent asthma

\author{
Catherine M Houghton*1,3, Naomi Lawson ${ }^{1}$, Zoe L Borrill1,3, \\ Claire L Wixon ${ }^{2}$, Sally Yoxall ${ }^{2}$, Stephen J Langley ${ }^{\wedge}$, Ashley Woodcock ${ }^{1,3}$ and \\ Dave Singh 1,3
}

Address: ${ }^{1}$ North West Lung Research Centre, South Manchester University Hospitals Trust, Manchester, UK, ${ }^{2}$ Research and Development, GlaxoSmithKline, Greenford, Middlesex, UK and ${ }^{3}$ Faculty of Medical and Human Sciences, The University of Manchester, Manchester, UK

Email: Catherine M Houghton* - cathhoughton@doctors.org.uk; Naomi Lawson - nlawson@meu.org.uk; Zoe L Borrill - zborrill@meu.org.uk; Claire L Wixon - claire.l.wixon@gsk.com; Sally Yoxall - sally.q.yoxall@gsk.com; Stephen J Langley - sjlangley@meu.org.uk; Ashley Woodcock - ashley.woodcock@manchester.ac.uk; Dave Singh - dsingh@meu.org.uk

* Corresponding author $\wedge$ Deceased

Published: 14 July 2007

Respiratory Research 2007, 8:52 doi:10.1 |86/1465-992/-8-52

This article is available from: http://respiratory-research.com/content/8/1/52

(C) 2007 Houghton et al; licensee BioMed Central Ltd.

This is an Open Access article distributed under the terms of the Creative Commons Attribution License (http://creativecommons.org/licenses/by/2.0), which permits unrestricted use, distribution, and reproduction in any medium, provided the original work is properly cited.
Received: 15 January 2007

Accepted: I 4 July 2007

\begin{abstract}
Background: This study compared the effect of inhaled fluticasone propionate (FP) with the combination of salmeterol/fluticasone propionate (SFC) on lung function parameters in patients with mild asthma.

Methods: Adult patients with mild persistent asthma ( $\geq 80 \%$ predicted $\mathrm{FEV}_{\mathrm{I}}$ ) receiving $200-500$ $\mu \mathrm{g}$ of BDP or equivalent were randomised to receive either FP $100 \mu \mathrm{g}$ or SFC $50 / 100 \mu \mathrm{g}$ twice daily from a Diskus ${ }^{\circledR}$ inhaler for four weeks. The primary outcome was the change from baseline in airway resistance (sRaw) at 12 hrs post dose measured by whole body plethysmography. Impulse oscillometry and spirometry were also performed.
\end{abstract}

Results: A comparison of the geometric mean sRaw at 12 hrs post dose in the SFC group to the FP group gave a ratio of $0.76(0.66-0.89, p<0.00 I)$ at week 2 and $0.81(0.71-0.94, p=0.006)$ at week 4. Similarly, significant results in favour of SFC for oscillometry measurements of resistance and reactance were observed. FEV, was also significantly superior at week 2 in the SFC group (mean difference $0.16 \mathrm{~L}, 95 \% \mathrm{Cl} ; 0.03-0.28, \mathrm{p}=0.015$ ), but not at week 4 (mean difference $0.17 \mathrm{~L}$, $95 \% \mathrm{Cl}-0.01-0.34, \mathrm{p}=0.060)$.

Conclusion: SFC is superior to FP in reducing airway resistance in mild asthmatics with near normal FEV, values. This study provides evidence that changes in pulmonary function in patients with mild asthma are detected more sensitively by plethysmography compared to spirometry

Trial registration number: NCT0037059I. 


\section{Background}

Clinical trials of drug treatments for asthma commonly use the spirometric assessment of $\mathrm{FEV}_{1}$ to assess improvements in lung function. $\mathrm{FEV}_{1}$ is a relatively simple and reproducible measurement that is required by regulatory authorities. However, in patients with mild asthma, $\mathrm{FEV}_{1}$ may be close to normal and is not as sensitive as body plethysmography and impulse oscillometry (IOS) for measuring small changes in lung function in response to broncodilators [1-3]. Furthermore, body plethysmography assesses airway resistance while IOS measures pulmonary resistance and reactance, properties not assessed by spirometry [3-6].

Combination therapies of inhaled corticosteroids (ICS) with a long acting beta agonist (LABA) are effective in the treatment of asthma. The combination of salmeterol and fluticasone propionate (SFC, Seretide $\mathrm{GSK}^{\mathrm{TM}}$ ) improves symptoms, lung function and exacerbation rates when compared to the same or double the dose of fluticasone propionate (FP) in symptomatic patients with asthma who have moderately impaired lung function $\left(\mathrm{FEV}_{1}<80 \%\right.$ predicted) [7-9]. However, there are less data regarding the effects of SFC in symptomatic patients with mild asthma who may have almost normal $\mathrm{FEV}_{1}$ values. The advantages of SFC over ICS alone in this subgroup is difficult to evaluate using $\mathrm{FEV}_{1}$, as this measurement is near normal. In the absence of studies using more sensitive pulmonary function measurements than $\mathrm{FEV}_{1}$, guidelines have favoured the use of ICS alone for mild asthma patients [10]. However, the benefits of combination therapy with SFC in patients with mild asthma may be more apparent if sensitive pulmonary function measurements, such as body plethysmography and IOS are used.

We report a comparison of the effects of SFC 50/100 $\mu \mathrm{g}$ twice daily compared to FP $100 \mu \mathrm{g}$ bd in patients with mild asthma already being treated with ICS. Our primary aim was to compare the changes in lung function, assessed by plethysmography, IOS and spirometry.

\section{Methods}

Study subjects

Patients with physician diagnosed asthma for at least six months who were receiving a stable total daily dose of ICS equivalent to 200-500 $\mu \mathrm{g}$ beclomethasone dipropionate (BDP) for at least 4 weeks prior to the study were enrolled. The inclusion criteria included an $\mathrm{FEV}_{1} \geq 80 \%$ predicted and demonstration of $\mathrm{a} \geq 30 \%$ decrease in sRaw in response to $400 \mu \mathrm{g}$ of inhaled salbutamol at screening. This reversibility criterion was based on previous data demonstrating that this magnitude of change in sRaw was significantly greater than within day variability [1]. Exclusion criteria were the use of parenteral, oral and nebulised steroids in the 4 weeks prior to the study or 12 weeks for depot corticosteroids and current smokers or ex smokers for $<12$ months. All female patients of childbearing potential were required to be using appropriate contraception and have a negative pregnancy test results at screening. All patients gave written informed consent and the study was approved by the south manchester ethics committee; reference number 02/SM/460.

\section{Study design and medication}

This was a single centre, randomised, double blind, parallel group trial conducted between December 2002 and April 2004. All patients were treated with FP $100 \mu \mathrm{g}$ bd through an Accuhaler/Diskus (GSK ${ }^{\mathrm{TM}}$ ) during a 2 week run in period. To be eligible for randomisation, subjects were required to have symptoms more than once a week, but not every day of the week during the run in period. At the end of the run in period, baseline measurements of pulmonary function and methacholine reactivity were performed. Subjects were then randomised to SFC 50/100 $\mu \mathrm{g}$ bd or FP $100 \mu \mathrm{g}$ bd via identical Accuhaler devices for a 4 week treatment period (Figure 1). Patients were provided with a salbutamol Accuhaler for as required use. Pulmonary function measurements were performed after the run in period (baseline) and after 2 and 4 weeks of treatment. These were performed in the morning before dosing with study medication (pre-dose), and at 2 hrs post-dose. No IOS data was collected at week 2 . Methacholine reactivity was assessed 2 hrs post-dose at week 4 . Patients were given diary cards in which to record morning and evening peak expiratory flow (PEF).

\section{Pulmonary function and methacholine challenge tests}

Pulmonary function tests were always performed in the same order: (1) IOS, (2) plethysmography and (3) spirometry. The deep inspiration required for spirometry may cause a temporary alteration in bronchial tone [11]
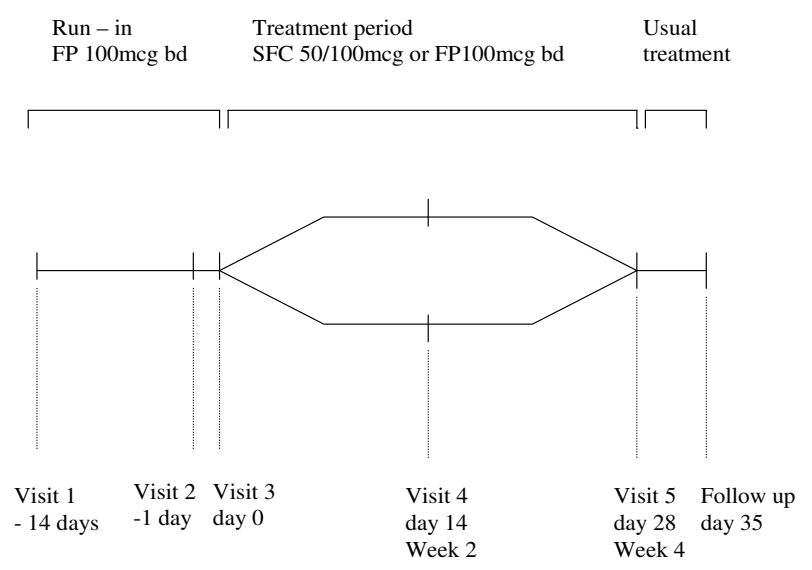

Figure I

Study flow chart. 
so resistance measures were made prior to spirometry. A full explanation and training in the performance of each lung function test was given to each subject prior to the study.

For IOS (Masterscreen IOS, Erich Jaeger, Hoechberg, Germany) subjects supported their cheeks to reduce upper airway shunting while impulses were applied during tidal breathing for 30 seconds. The mean of three readings of R5 and R20 (respiratory resistance at 5 and $20 \mathrm{~Hz}$ respectively), X5 (reactance at $5 \mathrm{~Hz}$ ) and RF (resonant frequency) were recorded. For plethysmography, sRaw and sGaw were measured in a constant volume plethysmograph (Sensormedics Vmax 6200) and the mean of 3 readings was recorded. For spirometry, $\mathrm{FEV}_{1}$ (volume expired over the first second) and MMEF (maximal mid expiratory flow rate) were performed (Masterscreen, Erich Jaeger) and the mean of 3 readings was recorded.

Methacholine challenge tests were performed as previously reported [12]. A De Vilbiss 646 nebulizer (Sunrise Medical; Wollaston, UK) and a Rosenthal dosimeter (PDS Research UK; Gravesend, UK) were used to deliver the methacholine. Three concentrations of methacholine chloride were used $(1.5 \mathrm{mg} / \mathrm{ml}, 12 \mathrm{mg} / \mathrm{ml}$ and $50 \mathrm{mg} / \mathrm{ml}$, Stockport Pharmaceuticals, UK) to administer doubling doses, starting from a dose of $0.015 \mathrm{mg}$ increasing to a final cumulative dose of $5.96 \mathrm{mg}$. The $\mathrm{PD}_{20}$ was calculated as thecumulative dose that produced a $20 \%$ decrease in $\mathrm{FEV}_{1}$ by interpolation.

\section{Statistical analysis}

The primary outcome measure was the morning pre-dose sRaw after 4 weeks treatment with SFC and FP. Based on previous studies a $20 \%$ difference in pre dose sRaw between the two treatment groups was identified as a clinically relevant difference [13]. A sample size of 18 evaluable subjects per group (36 evaluable subjects in total) would have $90 \%$ power to detect a difference of $20 \%$ between treatment groups in pre-study medication sRaw at 4 weeks of treatment, assuming a common standard deviation of $0.20 \mathrm{s.kPa}$ of natural log sRaw, at a 5\% twosided significance level. A sample size of 20 subjects per group would allow for an estimated treatment withdrawal rate of $10 \%$.

The differences between the effects of SFC and FP on pulmonary function measurements and methacholine reactivity were analysed by ANCOVA with covariates of age, gender, baseline measurement and treatment group. sRaw and sGaw were log transformed and least square means for the treatments were transformed back to the original scale and are presented as geometric means. Baseline PEF was defined as the mean of the daily values over the last 7 days of the 2 week run in period. Mean morning and evening PEF were calculated from all the available data from week 1 to 4 . Statistical analysis was performed on an Intention To Treat basis with all subjects randomised to treatment being included. If there was no data for the primary endpoint (sRaw) at week 4, the last observation from week 2 was carried forward. For analysis of bronchial hyperreactivity, only subjects who had a $20 \%$ decrease in $\mathrm{FEV}_{1}$ before or at the highest methacholine concentration at the end of the run in period and at week 4 (i.e. those with $\mathrm{PD}_{20} \leq 5.96 \mathrm{mg}$ ) were included.

\section{Results}

Fifty six patients were enrolled into the run in period, of which 13 did not meet the daily symptom score requirement, 3 did not complete the diary card correctly and 1 was non compliant with run in medication. The demography and lung function at screening (before run in) of the remaining 39 subjects who were eligible for randomisation is shown in Table 1. Baseline measurements of pulmonary function after the run in are shown in Table 2. There were 2 withdrawals following randomisation, one in each treatment group due to loss of study medication in he SFC group and medication running out in the FP group.

\section{Pre-dose pulmonary function Plethysmography}

SFC caused a significantly greater reduction in pre dose sRaw compared with FP at weeks 2 and 4 (Figure 2 shows adjusted body plethysmography data). The geometric mean pre dose sRaw was $24 \%$ lower in the SFC group compared with the FP group (ratio 0.76, 95\% CI; 0.66$0.89, \mathrm{p}<0.001$ ) at week 2 and $19 \%$ lower (ratio $0.81,95 \%$ CI; 0.71-0.94, $\mathrm{p}=0.006$ ) at week 4 . Similarly, there was a statistically significant greater increase in pre dose sGaw at week 2 and 4 in the patients receiving SFC compared with

Table I: Subject demographics at screening

\begin{tabular}{|c|c|c|}
\hline & $\begin{array}{c}\text { SFC } 50 / 100 \\
N=19\end{array}$ & $\begin{array}{l}F P 100 \\
N=20\end{array}$ \\
\hline Age & $38.4(9.8)$ & $41.8(14.7)$ \\
\hline \multicolumn{3}{|l|}{ Sex 1} \\
\hline Female & $10(53 \%)$ & $12(60 \%)$ \\
\hline Male & $9(47 \%)$ & $8(40 \%)$ \\
\hline Duration of asthma $\geq 15$ years & II $(58 \%)$ & $7(35 \%)$ \\
\hline$\%$ predicted $\mathrm{FEV}_{\mathrm{I}}$ & $93.4(9.0)$ & $95.3(11.4)$ \\
\hline $\mathrm{FEV}_{1}$ & $3.22(0.55)$ & $3.04(0.81)$ \\
\hline sRaw s.kPa* & $1.00(39.61)$ & $0.94(50.28)$ \\
\hline sGaw s $\mathrm{s}^{-1} \mathrm{kPa}$ & $1.29(152.11)$ & $1.07(50.47)$ \\
\hline $\begin{array}{l}\% \text { change in sRaw post } 400 \mu \mathrm{g} \\
\text { salbutamol }\end{array}$ & $-43.6(10.2)$ & $-38.4(7.0)$ \\
\hline
\end{tabular}

Data is mean (SD) except;

$*=$ geometric mean $(\mathrm{CV})$

$\mathrm{I}=$ number of subjects (percent) 
Table 2: Baseline (week 0 ) pulmonary function

\begin{tabular}{|c|c|c|}
\hline & $\begin{array}{c}\text { SFC } 50 / 100 \\
N=19\end{array}$ & $\begin{array}{l}F P 100 \\
N=20\end{array}$ \\
\hline sRaw s.kPa * & $0.86(42.0))$ & $0.91(42.15)$ \\
\hline sGaw s-1 $\mathrm{kPa}^{-1} *$ & $1.17(42.10)$ & I.II (4I.9I) \\
\hline $\mathrm{FEV}_{1}(\mathrm{~L})$ & $3.24(0.57)$ & $3.10(0.75)$ \\
\hline MMEF $\left(L \cdot s^{-1}\right)$ & $2.00(1.45)$ & $2.44(1.03)$ \\
\hline AM PEFR (L/min) & $484.02(105.38)$ & $467.50(117.64)$ \\
\hline PM PEFR (L/min) & 494.05 (101.27) & 475.52 (I I 2.54) \\
\hline $\mathrm{R} 5\left(\mathrm{kPa} \cdot \mathrm{L}^{-1} . \mathrm{s}\right)$ & $0.44(0.10)$ & $0.51(0.15)$ \\
\hline R20 (kPa. $\left.L^{-1} \cdot s\right)$ & $0.36(0.08)$ & $0.39(0.11)$ \\
\hline X5 (kPa.L-1.s) & $0.14(0.04)$ & $0.17(0.1)$ \\
\hline $\mathrm{RF}(\mathrm{Hz})$ & $15.29(4.84)$ & $16.67(6.35)$ \\
\hline $\mathrm{AHR}(\mathrm{mg}) *$ & 0.41 (348.8) & $0.37(372.7)$ \\
\hline
\end{tabular}

Data is mean (SD) except;

$*=$ geometric mean $(\mathrm{CV})$

those receiving FP (Figure 2). sGaw was 30\% greater at week 2 (ratio 1.31, 95\% CI; 1.13-1.51, p < 0.001) and $24 \%$ greater at week 4 (ratio 1.24, 95\% CI: $1.08-1.44, \mathrm{p}=$ 0.004 ) in the SFC group.

\section{Spirometry}

At week 2 there was a small increase in the pre-dose $\mathrm{FEV}_{1}$ with SFC, that was statistically significant compared with FP; mean difference 0.16L, 95\% CI; 0.03-0.28, p = 0.015 (Figure 3 shows adjusted FEV1 data). The mean difference at week 4 was $0.17 \mathrm{~L}$, which approached statistical significance (95\% CI -0.01-0.34, $\mathrm{p}=0.06)$. There were no significant differences in MMEF measurements between SFC and FP at week 2 (mean difference $1.1 \mathrm{~L} / \mathrm{sec}, 95 \% \mathrm{CI}$; $0.13-2.32, \mathrm{p}=0.08$ ) and week 4 (mean difference $0.11 \mathrm{~L} /$ sec, 95\% CI; -0.35-0.56, $\mathrm{p}=0.6)$.

\section{Impulse Oscillometry}

At week 4 there were statistically significant improvements in IOS measurements in the SFC group compared
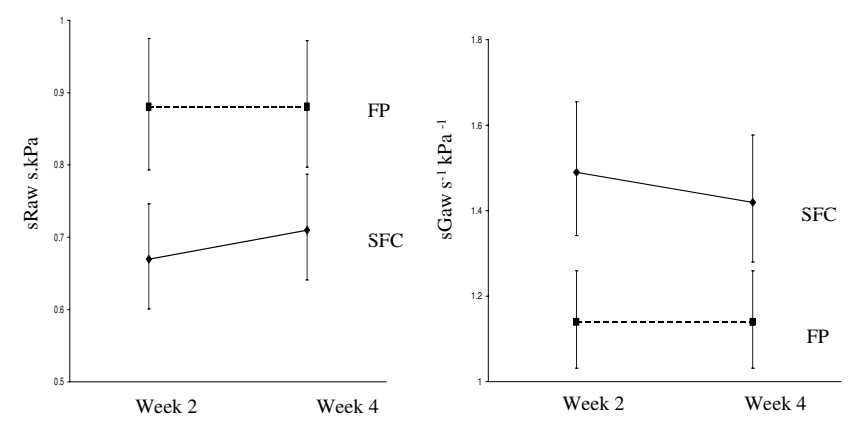

Figure 2

Comparison of sRaw and sGaw between SFC and FP groups. Data points = adjusted geometric mean at week 2 and 4 (ANCOVA adjusted for effects of gender age and baseline lung function). Error bars $=95 \%$ confidence intervals

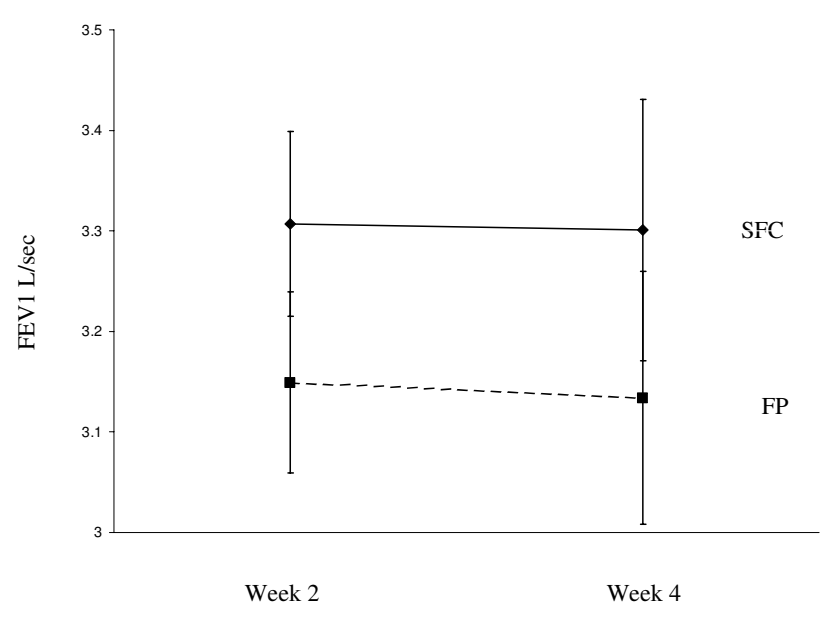

Figure 3

Comparison of FEV, between SFC and FP groups. Data points $=$ adjusted mean change at week 2 and 4 (ANCOVA adjusted for effects of gender age and baseline lung function). Error bars $=95 \%$ confidence intervals

with FP (Figure 4 shows adjusted IOS data). The mean RF at week 4 was $13.07 \mathrm{~Hz}$ (95\% CI; 11.3 - 14.84) in the SFC group and 17.65 (95\% CI; $15.99-19.3$ ) in the FP group. The mean difference in the resistance parameters $\mathrm{R} 5$ and R20 were $-0.11 \mathrm{kPaL}^{-1}$.s (95\% CI; -0.16- -0.06, p < 0.001 ) and $-0.06 \mathrm{kPaL}^{-1} \cdot \mathrm{s}$ (95\% CI; -0.09-0.02, p =0.001) respectively. The mean difference in the reactance parameters RF and X5 were -4.58 Hz (95\% CI; -7.01- -2.15, p < $0.001)$ and $-0.04 \mathrm{kPaL}^{-1} \cdot \mathrm{s}(95 \% \mathrm{CI} ;-0.07--0.01, \mathrm{p}=$ $0.019)$.

\section{Post-dose Pulmonary Function}

The improvement in lung function at 2 hrs after the first dose was greater in the SFC compared with the FP group; for the primary endpoint of sRaw the adjusted mean changes between pre and post dose were $36.4 \%$ and 7.1 $\%$ respectively. The adjusted mean (95\% CI) difference was $29.3 \%$ (20.7 to 37.9 ), p < 0.001. Pulmonary function measurements at 2 hrs post dose were stable over the treatment period, with data in both groups after 2 and 4 weeks dosing similar to measurements after the first dose (Table 3).

\section{PEF}

The mean morning and evening PEF analysed over weeks 1 to 4 was significantly greater $(21.6 \mathrm{~L} / \mathrm{min} 95 \% \mathrm{CI} ; 10.6$ - 32.7, $\mathrm{p}<0.001$ and $17.6 \mathrm{~L} / \mathrm{min}, 95 \% \mathrm{CI} ; 5.1-30.2, \mathrm{p}=$ $0.007)$ in the SFC group compared with the FP group.

\section{Airway hyperreactivity}

Twelve subjects in the SFC group and 16 in the FP group had $\mathrm{PD}_{20} \leq 5.96 \mathrm{mg}$ at the end of the run in period and at 


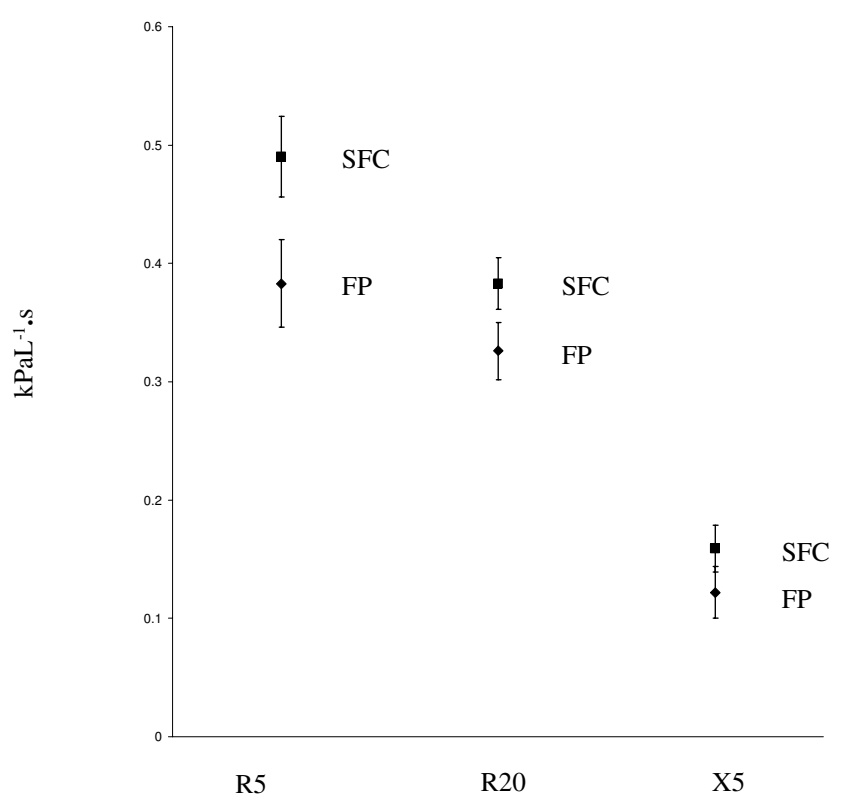

Figure 4

Comparison of R5, R20 and X5 between SFC and FP groups. Data points = adjusted geometric mean at week 4 (ANCOVA adjusted for effects of gender age and baseline lung function). Squares = FP. Diamonds $=$ SFC. Error bars $=$ $95 \%$ confidence intervals

Table 3: Lung function 2 hours post dose

\begin{tabular}{|c|c|c|c|}
\hline & & $\begin{array}{c}\text { SFC } \\
\text { mean }(95 \% \mathrm{Cl})\end{array}$ & $\begin{array}{c}\mathrm{FP} \\
\text { mean }(95 \% \mathrm{Cl})\end{array}$ \\
\hline \multirow[t]{3}{*}{ sRaw s.kPa } & Week 0 & $\begin{array}{c}0.53 \\
(0.46,0.62)\end{array}$ & $\begin{array}{c}0.84 \\
(0.73,0.98)\end{array}$ \\
\hline & Week 2 & $\begin{array}{c}0.56 \\
(0.47,0.67)\end{array}$ & $\begin{array}{c}0.85 \\
(0.72,1.01)\end{array}$ \\
\hline & Week 4 & $\begin{array}{c}0.56 \\
(0.48,0.67)\end{array}$ & $\begin{array}{c}0.77 \\
(0.65,0.91)\end{array}$ \\
\hline \multirow[t]{3}{*}{$\mathrm{sGaw} \mathrm{s}^{-1} \mathrm{kPa}^{-1}$} & Week 0 & $\begin{array}{c}1.88 \\
(1.61,2.21)\end{array}$ & $\begin{array}{c}1.19 \\
(1.02,1.39)\end{array}$ \\
\hline & Week 2 & $\begin{array}{c}1.80 \\
(1.51,2.14)\end{array}$ & $\begin{array}{c}1.18 \\
(1.00,1.39)\end{array}$ \\
\hline & Week 4 & $\begin{array}{c}1.78 \\
(1.50,2.12)\end{array}$ & $\begin{array}{c}1.3 \\
(1.10,1.54)\end{array}$ \\
\hline \multirow[t]{3}{*}{$\mathrm{FEV}_{\mathrm{I}}(\mathrm{L})$} & Week 0 & $\begin{array}{c}3.50 \\
(3.16,3.84)\end{array}$ & $\begin{array}{c}3.15 \\
(2.82,3.48)\end{array}$ \\
\hline & Week 2 & $\begin{array}{c}3.41 \\
(3.08,3.73)\end{array}$ & $\begin{array}{c}3.07 \\
(2.76,3.38)\end{array}$ \\
\hline & Week 4 & $\begin{array}{c}3.36 \\
(3.02,3.70)\end{array}$ & $\begin{array}{c}3.05 \\
(2.72,3.38)\end{array}$ \\
\hline
\end{tabular}

week 4. In these subjects, the ratio (SFC/FP) of the adjusted means for $\mathrm{PD}_{20}$ at week 4 was 1.57 (95\% CI: $0.70,3.54)$, with no difference between groups $(\mathrm{p}=0.25)$.

\section{Discussion}

We have studied patients with mild persistent asthma who are symptomatic despite being treated with ICS. Asthma guidelines advocate a step wise approach to pharmacological therapy in such patients, with the aim of optimizing asthma control defined by a range of clinical endpoints, including symptoms, exacerbation rates and pulmonary function. One possible step wise approach is the use of combined LABA and ICS in these patients. This is the first study to investigate the benefits on airway patency of combination therapy with SFC (50/100 $\mu \mathrm{g}$ bd) compared with ICS (FP $100 \mu \mathrm{g}$ bd) alone in a group of mild asthma patients.

Our primary endpoint was the sensitive measurement of sRaw using body plethysmography. The key findings were that SFC caused significant improvements in sRaw, sGaw and IOS resistance and reactance parameters at 12 hours post dose after 2 and 4 weeks treatment. At 2 weeks, a small but statistically significant difference was observed using $\mathrm{FEV}_{1}$, but not at 4 weeks. In this population of mild asthma patients, selected for reversibility using criteria based on sRaw, we have therefore shown that SFC 50/100 $\mu \mathrm{g}$ has greater benefits on pulmonary function compared with FP $100 \mu \mathrm{g}$, which are most apparent when using more sensitive methods than spirometry. Further studies are needed to determine if these pulmonary function findings are true in other asthma populations, and whether overall asthma control is improved by such a strategy.

In order to optimise asthma control in symptomatic mild asthma patients being treated with low dose ICS, it is possible to increase the ICS dose or add in a LABA. Using the SFC combination, we have proved that the addition of LABA has pulmonary function benefits compared to the same dose of ICS alone in this particular population. It would now be important to compare SFC to an increased dose of ICS alone in this population, as these are the 2 treatment options available in clinical practice.

The bronchodilator profile of salmeterol in asthma is well established, with maximal effects observed within 1-2 hrs $[13,14]$. In this study using SFC, it was therefore relevant to study both the maximal effects (at $2 \mathrm{hrs}$ post dose) as well as the effects at 12 hrs post dose, immediately prior to the next scheduled dose. We chose 12 hrs for the primary endpoint (sRaw) measurement, as this is the time point when the effects of SFC are most likely to be similar to FP. Thus, any superiority of SFC over FP at 12 hrs would indicate that the benefits of SFC are sustained over the full 12 hrs, and not just confined to the first 2 hrs post dose. 
Although $\mathrm{FEV}_{1}$ is the "gold standard" of clinical trials, we observed that substantial improvements in airway resistance occurred in mild asthmatics without a statistically significant change in $\mathrm{FEV}_{1}$ after 4 weeks treatment. We have previously shown that body plethysmography is a sensitive measurement of bronchodilation in mild asthmatics i.e. although body plethysmography has increased variability compared to $\mathrm{FEV}_{1}$, it is also more sensitive to changes in airway tone, and so was able to detect changes caused by $10 \mu \mathrm{g}$ salbutamol while there was no change in $\mathrm{FEV}_{1}[1]$. The current study provides further evidence that changes in pulmonary function in patients with mild asthma are detected more sensitively by plethysmography compared to spirometry $[1,2]$.

We did not measure FEV1 reversibility at screening. In the SFC group, there was an improvement in pulmonary function of $260 \mathrm{mls}$ after the first dose, equivalent to $8 \%$ reversibility. A higher degree of FEV1 reversibility would not be expected, as the baseline FEV1 was approximately $94 \%$ predicted.

Body plethysmography is more time consuming compared to spirometry, and is a more complex technique that requires a greater degree of operator training. However, it is clear that body plethysmography offers advantages in terms of sensitivity and we encourage its use in clinical trials of mild asthmatics [1-3,15]. The demonstration of improvements in airway resistance in patients with mild asthma is important, because it suggests that even in the context of minimal evidence of lung function impairment using spirometry, there is significant reversible disease activity that can be detected by measures of lung function that are more sensitive than those routinely used in clinical practice.

Involvement of the small airways, even in patients with mild asthma is increasingly recognised [16]. Improved deposition of inhaled corticosteroid in the small airways may lead to a clinical benefit by reducing the persistent inflammation seen in these airways [16]. It has been suggested that combination therapy may result in enhanced delivery of inhaled corticosteroid to the peripheral airways [17]. Furthermore LABA's may have a direct bronchodilator effect in the small airways [17]. Frequency dependant changes in resistance and compliance have been demonstrated in small airway disease $[18,19]$. It has been suggested that oscillometry is a sensitive measure of small airway dysfunction as a range of frequencies are employed and changes in R5, X5 and RF may reflect small airway physiology [20-22]. Thus, the changes in IOS demonstrated in this study may indicate beneficial small airway effects of SFC. There was no improvement in the spirometric measurement of MMEF, which has also been suggested to be an indicator of small airway function. This is likely to be due to the increased variability of MMEF compared to IOS causing reduced sensitivity [1]. The use of IOS is increasing in clinical practice, and the current study shows a valuable application of this method for detecting subtle but important effects of drugs that cannot be measured by standard spirometry.

This study produced some additional findings concerning the use of combination therapy. We found that post dose pulmonary function measurements were stable for 4 weeks in both groups. There have been some concerns about desensitisation to the effects of long-acting beta ${ }_{2}$ agonists after prolonged treatment [23]. However, longterm studies up to 12 months duration have shown no evidence of tachyphylaxis or tolerance to the bronchodilator effects of salmeterol $[24,25]$. The current study also did not observe desensitisation, as $2 \mathrm{hr}$ post dose lung function measurements in mild asthmatics treated with SFC were stable over a 4 week period.

There was a trend to an improvement in airway hyper reactivity (AHR) from baseline in the SFC treatment group but this was not significant. The current study did not enrol patients based on an inclusion criterion of AHR, and was not statistically powered to evaluate changes in AHR, as AHR was a secondary endpoint. Further studies powered to assess AHR as a primary endpoint are required to assess any potential benefit of SFC compared to FP alone on AHR in this patient population. However, a recent study has shown in mild to moderate patients that SFC improved AHR to a significantly greater extent than FP or salmeterol alone [26].

\section{Conclusion}

It is recognised that a substantial number of patients have mild persistent asthma associated with significant morbidity $[27,28]$. We have clearly shown that SFC has beneficial effects on lung function in patients with mild asthma that are not observed with ICS alone. These benefits of SFC therapy were sensitively demonstrated by body plethysmography and IOS. Further long term studies in mild asthma are required to ascertain the relationship between the improvements in lung function observed in the current study using SFC and clinical parameters such as symptoms and exacerbation rates.

\section{Competing interests}

Catherine Houghton has received travel grants from GlaxoSmithKline (GSK) and Astra Zeneca (AZ) and support for a conference from Chiesi. Naomi Lawson has no financial conflict of interest to declare. Zoe Borrill has received travel grants from GlaxoSmithKline (GSK) and support for a conference from Chiesi. Claire Wixon and Sally Yoxall are employees of GSK the manufacturer of SFC. Ashley Woodcock has received consultancy fees from 
GSK, Chiesi, Novartis, Schering Plough and Oriel Pharmaceuticals, research grants from GSK, Chiesi and Schering and support for conference attendance from GSK. Dave Singh has received lecture fees from AZ,GSK and Merck Sharp Dome, research grants fromGSK and AZ andsupport for conference attendance from Boehringer and AZ.

\section{Authors' contributions}

All authors participated in the study design, $\mathrm{CMH}, \mathrm{NL}$ and $\mathrm{ZB}$ coordinated the study and collected the data. SY performed the statistical analysis. $\mathrm{CMH}, \mathrm{CW}, \mathrm{SY}, \mathrm{DS}$ and AAW analysed and interpreted the data. CMH drafted the manuscript and all authors read and approved the final manuscript.

\section{Acknowledgements}

This study was funded by Glaxo Smith Kline. GSK performed the statistical analysis and were involved in the study design, interpretation of the data and the decision to submit the paper for publication.

\section{References}

I. Houghton CM, Woodcock AA, Singh D: A comparison of lung function methods for assessing dose-response effects of salbutamol. Br J Clin Pharmacol 2004, 58: I34- I4 I.

2. Houghton CM, Woodcock AA, Singh D: A comparison of plethysmography, spirometry and oscillometry for assessing the pulmonary effects of inhaled ipratropium bromide in healthy subjects and patients with asthma. Br J Clin Pharmacol 2005, 59: I52-159.

3. Tattersfield AE, Keeping IM: Assessing change in airway calibre - measurement of airway resistance. Br J Clin Pharmacol 1979, 8:307-319.

4. Goldman MD: Clinical application of forced oscillation. Pulm Pharmacol Ther 200I, I 4:341-350.

5. Pride NB: Forced oscillation techniques for measuring mechanical properties of the respiratory system. Thorax 1992, 47:317-320.

6. Hellinckx J, Cauberghs M, de Boeck K, Demedts M: Evaluation of impulse oscillation system: comparison with forced oscillation technique and body plethysmography. Eur Respir J 200 I, I 8:564-570.

7. van Noord JA, Schreurs AJ, Mol SJ, Mulder PG: Addition of salmeterol versus doubling the dose of fluticasone propionate in patients with mild to moderate asthma. Thorax 1999, 54:207-2I 2.

8. Ind PW, Dal Negro R, Colman NC, Fletcher CP, Browning D, James $\mathrm{MH}$ : Addition of salmeterol to fluticasone propionate treatment in moderate to severe asthma. Respir Med 2003, 97:555-562.

9. Matz J, Emmett A, Rickard K, Kalberg C: Addition of salmeterol to low-dose fluticasone versus higher-dose fluticasone: An analysis of asthma exacerbations. J Allergy Clin Immunol 200I, I 07(Suppl 5):783-789.

10. Global Initiative for Asthma (GINA): Global strategy for asthma management and prevention. In NHLBI Workshop Report National Institutes for Health National Heart, Lung and Blood Institute; 2002. NIH Publication Number 02-3659.

II. Pellegrino R, Sterk PJ, Sont JK, Brusasco V: Assessing the effect of deep inhalation on airway calibre: a novel approach to lung function in bronchial asthma and COPD. Eur Respir J 1998, 12:1219-1227.

12. Langley SJ, Holden J, Derham A, Hedgeland P, Sharma RK, Woodcock A: Fluticasone propionate via the Diskhaler or hydrofluoroalkane-134a metered-dose inhaler on methacholine-induced airway hyperresponsiveness. Chest 2002, I 22:806-8I I.

13. van Noord JA, Smeets JJ, Raaijimaker JAM, Bommer AM, Maesen FP: Salmeterol versus formoterol in patients with moderately severe asthma: onset and duration of action. Eur Respir J 1996, 9:1684-1688.
14. Palmqvist M, Perrson G, Lazer L, Rosenborg J, Larsson P, Lotvall J: In haled dry-powder formoterol and salmeterol in asthmatic patients: onset of action, duration of effect and potency. Eur Respir J 1997, 1 0:2484-2489.

15. Van Noord JA, Smeets J, Clement J, van de Woestijne KP, Demedts $\mathrm{M}$ : Assessment of reversibility of airflow obstruction. $\mathrm{Am} J$ Respir Crit Care Med 1994, I 50:55 I-554.

16. Martin RJ: Therapeutic significance of distal airway inflammation in asthma. J Allergy Clin Immunol 2002, I09(Suppl 2):S447-S460.

17. Currie GP, Stenback S, Lipworth BJ: Effects of fluticasone vs. fluticasone/salmeterol on airway calibre and airway hyperresponsiveness in mild persistent asthma. $\mathrm{Br} J$ Clin Pharmacol 2003, 56: II-17.

18. Mead J: Contribution of compliance of airways to frequencydependent behaviour of lungs. J Appl Physiol 1969, 26:670-3.

19. De La Hoz RE, Berger KI, Klugh TT, Friedman-Jimenez G, Goldring RM: Frequency depndance of compliance in the evaluation of patients with unexplained respiratory symptoms. Respir Med 2000, 94:22I-7.

20. van Noord JA, Clement J, van de Woestijne KP, Demedts M: Total respiratory resistance and reactance in patients with asthma, chronic bronchitis, and emphysema. Am RevRespir Dis I99|, I43(5 Pt I):922-927.

21. Bouaziz N, Beyaert C, Gauthier R, Monin P, Peslin R, Marchal F: Respiratory system reactance as an indicator of the intrathoracic airway response to methacholine in children. Pediatr pulmonol 1996, 22:7-13.

22. Skloot G, Goldman M, Fishler D, Goldman C, Schechter C, Levin S, Teirstein A: Respiratory assessment and physiological symptoms of ironworkers at the world trade center disaster site. Chest 2004, I 25: I 248-55

23. Cheung D, Timmers MC, Zwiderman AH, Bel EH, Dijkman JH, Sterk PJ: Long-term effects of a long-acting beta2-adrenoceptor agonist, salmeterol, on airway hyperresponsiveness in patients with mild asthma. N Engl J Med 1992, 327:I I98-I 203.

24. Britton MG, Earnshaw JS, Palmer JBD: A twelve month comparison of salmeterol and salbutamol in asthmatic patients. Eur Respir J 1992, 5: 1062-67.

25. Lundback B, Rawlinson DW, Palmer JBD: Twelve month comparison of salmeterol with salbutamol as dry powder formulations in asthmatic patients. Thorax 1993, 48: 148-53.

26. Lundback B, Ronmark E, Lindberg A, Jonsson AC, Levsson LG, Petavy $F$, James $M$ : Control of mild to moderate asthma over I-year with the combination of salmeterol and fluticasone propionate. Respir Med 2006, 100:2-10.

27. O'Byrne PM, Barnes PJ, Rodriguez-Roisin R, Runnerstrom E, Sandstrom T, Svensson K, Tatteresfield A: Low dose inhaled budesonide and formoterol in mild persistent asthma: the OPTIMA randomized trial. Am J Respir Crit Care Med 2001, I 64:I392-I397.

28. Zeiger RS, Bird SR, Kaplan MS, Pearlman DS, Schatz M, Bird S, Hustad $C$, Edelman J: Short-term and long-term asthma control in patients with mild persistent asthma receiving montelukast or fluticasone: a randomized controlled trial. Am J Med 2005, I | 8:649-647.

Publish with Biomed Central and every scientist can read your work free of charge

"BioMed Central will be the most significant development for disseminating the results of biomedical research in our lifetime. "

Sir Paul Nurse, Cancer Research UK

Your research papers will be:

- available free of charge to the entire biomedical community

- peer reviewed and published immediately upon acceptance

- cited in PubMed and archived on PubMed Central

- yours - you keep the copyright 